HIGH RANKING FEMALES BIAS THEIR INVESTMENT IN FAVOUR

OF MALE CALVES IN CAPTIVE AMMOTRAGUS LERVIA

\author{
JORGE CASSINELLO* \\ Estación Experimental de Zonas Aridas (CSIC) \\ c/ General Segura 1,04001-Almería (Spain)
}

Short title: Biased maternal investment in Ammotragus

* All correspondance and proofs should be addressed to: J. Cassinello, Estación Experimental de Zonas Aridas (CSIC), c/General Segura 1, 04001 Almería, Spain. Tel: +50 276400. Fax:+50 277100. Email: cass@cica.es 
SUMMARY

2 Calf suckling behaviour is a valid measure of maternal investment in the

3 Saharan arrui, Ammotragus lervia sahariensis, since this variable is

4 strongly correlated with the inter-birth interval. High ranking females

5 allocate their resources preferably towards their sons, as the average

6 suckling rate is significantly higher in male calves than in female calves

7 during their first month of life, when maternal investment reaches the

8 highest values of the whole lactation period. However, average suckling

9 bout duration shows no sex differences. Some maternal behaviours, such as

10 sniffing and licking, are strongly correlated with suckling events. Only

11 during calves' first week does the mother assume the responsibility for

12 maintaining proximity, but from the following week on the calves are the

13 main responsible for maintaining it. In addition, when the calves are one

14 month old, high ranking females tend to maintain a stronger link with their

15 male calves. Female calves spend more time with their mothers than male

16 calves during their first month of life, provided that the mother is holding a

17 rank inferior to $60 \%$; otherwise, the very opposite occurs, male calves

18 being close to their mothers for longer, even from their first week of life.

19 Finally, the higher the maternal rank the higher the proportion of male

20 calves delivered.

21 Key words: Ammotragus, Ungulates, Parental Investment, Sex ratio 
24 According to Trivers and Willard's (1973) hypothesis on parental 25 investment, in polygynous mammals those females in better physical 26 conditions, i.e. with a greater ability to invest, should bias their investment 27 towards male offspring, provided that son's reproductive success is mainly 28 determined by maternal investment (Clutton-Brock and Albon 1982; 29 Gomendio et al. 1990). There are two ways to accomplish this biased 30 investment, either by allocating the resources preferably to one sex (Reiter 31 et al. 1978), or by an adaptive adjustment of the sex ratio at birth (Trivers 32 and Willard 1973); both strategies are not exclusive. Nevertheless, in those 33 cases where maternal investment has a stronger effect on daughters' 34 eventual reproductive success, natural selection will favour those mothers 35 that invest more in their daughters, even when the variance in males' 36 reproductive success is greater.

37 In social species, where hierarchical status plays a significant role, 38 high ranking individuals benefit in many ways by having priority access to 39 vital and reproductive resources (e.g. Clutton-Brock et al. 1984, 1986; 40 Meikle et al. 1984; Bulger and Hamilton 1987; Wierenga 1990; Deutsch 41 and Lee 1991; Johnson et al. 1991; Alados and Escós 1992); consequently, 42 a relationship between social rank and reproductive success is expected.

43 Cassinello and Alados (1996) have recently pointed out that there is 44 indeed a positive relationship between social rank and reproductive success 45 in the Saharan arrui, Ammotragus lervia sahariensis, high ranking females 46 giving birth to heavier sons than do low ranking ones (Cassinello 1994). In 47 this paper I examine the secondary sex ratio and assess sex differences in 48 relation to several maternal behaviours that reflect maternal care (see 49 Clutton-Brock 1991), such as the proportion of time suckling, average 50 suckling duration, sniffing and licking frequency, Hinde's proximity index 51 (Hinde and Atkinson 1970) and proportion of time per sample that mother 
52 and offspring spend together. My aim is to determine whether mothers

53 holding high social ranks bias their care towards their sons, as could be 54 expected on theoretical grounds.

METHODS

\section{The Study Population}

58 The population of Saharan arrui living in captivity in the Estación

59 Experimental de Zonas Aridas, EEZA (Higher Council for Scientific

60 Research, CSIC), Almería, Spain, comes from three founder individuals

61 that were brought from western Sahara in 1975, two males and one female 62 (Alados and Vericad 1993). Since then, and in spite of a high degree of 63 inbreeding (Alados et al. 1988), the Saharan arrui has been breeding very 64 successfully in Almería (see Cassinello 1994). At the present time there are 65 five herds and 156 individuals. The study herd was made up by 17 males 66 and 26 females at the beginning of the study, and 33 males and 43 females 67 at the end of it. This herd has now become an all-males group, as the 68 current EEZA management programme is primarily focused on preventing 69 an excessive number of animals, inasmuch as re-introductions to the 70 innative land are facing quite strong political difficulties. This subspecies 71 used to be widespread over various localities in the North of Africa (see 72 Gray 1985), but at present it is presumably extinct in the wild (Alados and 73 Vericad 1993).

\section{Sampling Method}

76 Since the population of Saharan arrui was established in Almería, members 77 of the staff of the EEZA are recording a series of data from every new78 born: birth date, parturition type (single or twin), sex, body weight, 79 identification of father and mother, and inbreeding coefficient (see Wright 80 1922; Ballou 1983). A number is also assigned to every animal using 
81 plastic tags attached to their ears. During 1990, 1991 and 1992 I have been

82 sampling behaviour in order to clarify the relationship between mother and

83 offspring, according to the sex of the calf and the social rank of the mother.

84 The social ranks of all the 16 lactating females of the study herd were

85 calculated following the matrix method established by Scott (1980) and 86 Lamprecht (1986) (Cassinello 1995).

87 During sampling I was able to monitor the whole herd from an 88 elevation nearby, so the animals were not disturbed. I used a telescope to 89 identify the individuals and a field computer Psion Organiser II to register 90 a range of behaviours, which includes the ones mentioned below (see also 91 Haas 1959; Habibi 1987).

92 Approaching and staring at refer to the same concept, i.e. an 93 individual focusing his/her attention on other groupmate or a place; 94 whereas departing implies leaving it. I have defined proximity as the 95 approaching movement which leads to a distance between two arruis of 96 one adult female body-length or less; whereas departure would occur when 97 such movement leads to a distance of more than one body-length (Lickliter 98 1984; Ralls et al. 1987). Studying carefully every event I have defined as 99 initiator of an action of proximity/departure the individual that, either by 100 approaching/staring at or departing from another one, causes that both 101 arruis end up at a distance of $\leq 1$ or $>1$ body-length, respectively. On the 102 other hand, Hinde's proximity index (Hinde and Atkinson 1970) was used 103 to assess who was mainly responsible for maintaining proximity, the 104 mother or the calf. This index refers to the difference between the 105 proportions of approaches and departures carried out by the calf, and it has 106 been calculated for weeks and months, i.e. all the approaches and 107 departures executed by mother and calf during calf's first week/month have 108 been included in the calculation of a first value for the proximity index. 109 This calculation was repeated for the second week/month and so on. 
110 Grooming (licking and sniffing) and gnawing (a series of mild

111 gnaws or chews usually carried out by the calves on their mothers or other

112 calves, and which could be related to attachment) were other behaviours

113 recorded to assess the relationship between mother and calf.

114 Samples were taken during the evening, when the animals were 115 more active, notably adult females and calves (David Morgan pers. comm., 116 pers. obs.). Focal sampling was used to record mother and calf behaviour

117 (Altmann 1974; Martin and Bateson 1986), each sample being 20 minutes 118 long. All the focals taken successively form a sampling period. Every 119 female which gave birth during 1990, 1991 or 1992 was sampled four

120 times a week during her calf's first two months of life; during the rest of the 121 lactation period sampling was carried out 1.5 times per week. All mother122 calf interactions and the ones between them and other groupmates were 123 recorded during the focals. Also, during each sampling period, ad libitum 124 sampling (Altmann 1974; Martin and Bateson 1986) was used to record all 125 suckling and withdrawing events carried out by non-focal individuals, in 126 order to assess more precisely both the maternal investment and 127 hierarchical status, respectively. This sampling technique was possible due 128 to the optimal conditions under which the animals were observed, which 129 allowed me to monitor the whole herd without missing any conspicuous 130 interaction, such as suckling and withdrawing. During focal sampling and 131 every 5 minutes, the distance between the focal mother and her calf was 132 registered, using a female adult body-length as unit (see above).

133 Suckling behaviour was assessed through two measures: suckling 134 duration of each bout and proportion of time suckling per sampling period 135 (the total suckling time divided by the total observation time), which is 136 equivalent to Hass' (1990) average suckling rate, a term which is also used 137 here. The other behaviours are represented by frequencies, i.e. the number 138 of times an event occurred per minute, except the distance between mother 
139 and calves, which is represented by the proportion of time spent at a

140 particular distance $(1,2 \ldots$ body-lengths $)$.

141 A total of 26 mother-calf pairs were sampled, of which 10 were 142 twins (males:females $=4: 6$ ) and 16 single calves (9:7); but, due to 143 stillbirths and early deaths, as well as a case of adoption (Cassinello, 144 unpublished data), there were in practice 8 calves who shared their nursing 145 with a sibling (4:4) and 18 single calves (9:9).

147 Analyses

148 Whenever possible parametric tests have been run, using in some instances 149 transformations when the dependent variable was not normally distributed 150 (Zar 1984). In order to use some continuous variables as factors in the 151 analysis of variance, I had to form sub-groups or categories. This was the 152 case of female social rank, which was divided in four ranking groups 0-29, 153 30-59, 60-89 and 90-100\%. Starting from 16 females, the two highest 154 ranking ones (ranks 90 to 100\%) formed a group, based upon their 155 distinctive behaviour (they were scarcely threatened by adult males; 156 Cassinello, unpublished data); whereas the remaining females were 157 distributed in equal size ranking groups: 0-29\%, 30-59\% and 60-89\%, 158 which included respectively five, four and five females. It is also 159 noteworthy that the females from the lowest ranking group (0-29\%) never 160 gave birth to twins, and the ones from the 30-59\% ranking group only gave 161 birth to single calves or female twins (Cassinello, unpublished data). In 162 some analyses, data of different calves from the same mother were 163 considered as independent, because a previous analysis of the intra and 164 inter-group variance showed for all the behavioural variables that the inter165 group variance was not greater than the intra-group variance. 
168 Parental Input vs Parental Investment

169 By definition, parental investment implies a reproductive cost for the 170 parents (Trivers 1972). Therefore, whether the measure of parental input 171 (sensu Evans 1990) implies an effect on fertility or not should be firstly

172 determined. The relationship between the total lactation effort (the average 173 suckling rate) and the interval of time to the next birth was analysed. Fig. 1 174 shows a strong and statistically significant relationship (the inter-birth 175 interval was normally distributed): $\mathrm{N}=8, \mathrm{R}^{2}=0.91, \mathrm{p}=0.0003$, the higher the 176 average suckling rate, the longer the interval. Therefore, the suckling 177 behaviour used should be considered as a reliable measure of maternal 178 investment in the Saharan arrui.

179

\section{Analysis of Suckling Behaviour}

181 The analysis of suckling behaviour was assessed by means of both average 182 suckling rate and suckling duration. To carry out parametric tests they were 183 transformed into the logarithm and arcsine of the square root, respectively 184 (Zar 1984). The changes of these variables over the total lactation period is 185 shown in Fig. 2, from which the high values reached during the first month 186 of a calf's life become evident (Student $t$ test between months 0 and 1 for 187 average suckling duration: $\mathrm{df}=21, \mathrm{t}=7.00, \mathrm{p}<0.0001$; and proportion of time 188 suckling: $\mathrm{df}=21, \mathrm{t}=8.80, \mathrm{p}<0.0001)$. This pattern shows that maternal 189 investment was particularly important during a calf's first month, so that 190 the following analyses were centred on this period.

191 The average suckling rate was significantly higher in one moth old 192 males born to mothers holding social ranks $\geq 60 \%(\mathrm{~F}(1,15)=7.55, \mathrm{p}=0.01)$; 193 but when a mother held a rank lower than $60 \%$ there were no differences 194 between male and female calves $(F(1,7)=0.07, p=0.80)$ (see Fig. 3).

195 Concerning average suckling duration, the analysis of variance did show 196 no sex differences (maternal rank $\geq 60 \%$ : $\mathrm{F}(1,14)=2.28$, $\mathrm{p}=0.15$; maternal 
197 rank < 60\%: $\mathrm{F}(1,7)=3.79, \mathrm{p}=0.09)$. From the calves' second month of life

198 there were no sex differences either in maternal investment.

199 The grooming behaviour (sniffing and licking) performed by the 200 mothers towards their calves was particularly frequent during the first days 201 following the birth, decreasing thereafter (Spearman correlation: sniffing, $202 \mathrm{n}=163$, rho $=-0.23, \mathrm{p}=0.004$; licking, $\mathrm{n}=163$, rho $=-0.49, \mathrm{p}<0.0001)$. This 203 pattern was not followed by mother's gnawing behaviour $(\mathrm{N}=163$, $204 \mathrm{rho}=0.05, \mathrm{p}=0.52$ ), which was markedly less frequent. Sniffing and licking 205 were not related to maternal rank (sniffing: $\mathrm{F}(1,24)=0.06$, $\mathrm{p}=0.81$; licking: $206 \mathrm{~F}(1,24)=0.51, \mathrm{p}=0.48$ ), nor to calf sex (sniffing: $\mathrm{F}(1,24)=0.20, \mathrm{p}=0.65$; 207 licking: $F(1,24)=0.26, p=0.62)$. The scarcity of data prevented testing these 208 relationships for gnawing behaviour. By pooling the sniffing, licking and 209 gnawing data I created a new variable which might be called "caressing", 210 and which refers to the mother's care towards her calf. This variable was 211 positively related to the average suckling rate $\left(\mathrm{N}=26, \mathrm{R}^{2}=0.24, \mathrm{p}=0.01\right)$.

212 Calves' gnawing behaviour addressed towards their mothers was 213 relatively frequent during the sampling period, although a substantial 214 decrease could be seen from the third month on $(\mathrm{N}=172, \mathrm{U}=2686$, $215 \mathrm{U}^{\prime}=3981, \mathrm{p}=0.006$ ). During their first two months of life female calves 216 born to low ranking (rank $<60 \%$ ) mothers gnawed more frequently than 217 male calves did, but the result was not statistically significant $(\mathrm{F}(1,7)=0.87$, $218 \mathrm{p}=0.38$ ); males and females born to high ranking mothers did not differ in 219 their gnawing frequency $(\mathrm{F}(1,15)=0.35, \mathrm{p}=0.56)$.

\section{Study of Proximity and Spatio-Temporal Patterns}

222 The study of proximity leads to two main questions: who is responsible for 223 it and for how long is it mantained. To elucidate the first question I used 224 Hinde's proximity index (Hinde and Atkinson 1970), which estimates the 225 difference between the percentage of approaches and withdrawals carried 
226 out by calves. It ranges from -1 to +1 ; the positive values denote a more 227 active role played by the calf, whereas the negative ones an active role 228 played by the mother. A value of 0 indicates that both, mother and calf, are 229 equally responsible for maintaining proximity. Concerning how long 230 mother and calf stay in proximity, I analysed the proportion of time that 231 they were at different distances (measured as adult female body-lengths).

232 The relationship between the weekly Hinde's proximity index and 233 calf's age is shown in Fig. 4. Only during calves' first week were mothers 234 responsible for maintaining proximity (analysis of variance for 0-7 weeks: $235 \mathrm{~F}(7,83)=3.25, \mathrm{p}=0.004)$. During calves' first month of life a negative 236 relationship was found between Hinde's proximity index and maternal rank 237 for male $\left(\mathrm{N}=11, \mathrm{R}^{2}=0.40, \mathrm{p}=0.04\right)$, but not for female calves $(\mathrm{N}=11$, $238 \mathrm{R}^{2}=0.002, \mathrm{p}=0.91$ ) (see Fig. 5).

239 In order to determine the distances kept by mother and calf, an 240 analysis in which the proportion of time they were at different distances (0241 1, 2-3, 4-5, 6-10 and >10 body-lengths) was carried out. Throughout the 242 whole lactation period the proportion of time mother and calf were at a 243 distance of 0-1 body-lengths was not correlated with the average suckling 244 rate $(\mathrm{N}=808, \mathrm{rho}=0.05, \mathrm{p}=0.18)$; indeed, many suckling events took place 245 just after mother and calf had been several body-lengths away (pers. obs.). 246 On the contrary, being at a distance of more than 10 body-lengths 247 decreased the probabilities of a suckling event to take place $(\mathrm{N}=808$, rho=$2480.07, \mathrm{p}=0.04)$. On the other hand, when the calf was more than one body249 length away from its mother, grazing frequency increased $(\mathrm{N}=814$, rho=250 0.23, p<0.0001). One week and one month old calves were found 251 predominantly at 0-1 body-lengths from their mother (Friedman's test for 252 first week: $\mathrm{df}=4, \chi^{2}=21.47, \mathrm{p}=0.0003$; first month: $\mathrm{df}=4, \chi^{2}=66.63$, $253 \mathrm{p}<0.0001)$. During calf's first month low ranking mothers (rank < 60\%) 254 spent more time close to their calves than mothers of a higher status (see 
255 Fig. 6; 0-1 body-lengths: $F(1,23)=8.60, p=0.007 ; 2-10$ body-lengths:

$256 \mathrm{~F}(1,23)=4.45, \mathrm{p}=0.046$; more than 10 body-lengths: $\mathrm{F}(1,23)=1.61, \mathrm{p}=0.22)$.

257 But after splitting the analysis by calf sex some differences were seen:

258 male calves were found close to their mother more frequently than female

259 calves provided that their mother's rank was $\geq 60 \%(\mathrm{~F}(1,14)=5.16, \mathrm{p}=0.04)$.

260 The opposite occurred when the rank was lower than $60 \%$, i.e. female

261 calves were found close to their mother for longer: $F(1,7)=6.44, p=0.04$ )

262 (see Fig. 7). Moreover, already one week old male calves born to high

263 ranking females spent more time close to their mother than female calves

$264(\mathrm{~F}(1,15)=24.79, \mathrm{p}=0.0002)$.

265

266 Analysis of the Secondary Sex Ratio

267 The analysis of the secondary sex ratio (no. males/no. females, at birth) has

268 an important drawback, as it does not include those mothers which have 269 only delivered male calves. In order to prevent this, a first regression 270 analysis was run to test whether the percentage of male infants depended 271 on their mother's rank, whereas a second regression analysis tested the 272 relationship between the absolute number of males and females delivered 273 and their mother's rank. I considered individual females who contributed 274 three or more offspring to the sample as well as the average ranks held by 275 them (see Berman 1988), as rank may vary during the reproductive life 276 (Cassinello 1995). The result of the analysis of the percentage of male 277 calves was statistically significant $\left(\mathrm{N}=10, \mathrm{R}^{2}=0.42, \mathrm{p}=0.04\right)$, although the 278 significance depended critically on just one data point (see Fig. 8). The 279 absolute number of male calves was instead clearly related to maternal $280 \operatorname{rank}\left(\mathrm{N}=10, \mathrm{R}^{2}=0.55, \mathrm{p}=0.01\right)$ (Fig. 9), but not the female calves $(\mathrm{N}=10$, $\left.281 \mathrm{R}^{2}=0.005, \mathrm{p}=0.85\right)$ (Fig. 10).

282 The percentage of male infants was not related, on the other hand, to 283 the mother's age $\left(\mathrm{N}=10, \mathrm{R}^{2}=0.12, \mathrm{p}=0.33\right)$, and did not differ significantly 
284 between single and twin births (singles: 53\% ( $\mathrm{N}=164)$, twins: 45\% ( $\mathrm{N}=74)$;

285 Mann-Whitney test: $\mathrm{U}=5555, \mathrm{p}=0.30$ ), so that we can assume that twinning 286 has no effect on the sex ratio. Finally, calf sex was not related to the inter287 birth interval either, as Student $t$ test showed both for the sex of the 288 previous birth $(\mathrm{df}=129, \mathrm{t}=0.80, \mathrm{p}=0.43)$ and the sex of the current birth $289(\mathrm{df}=122, \mathrm{t}=1.40, \mathrm{p}=0.16)$.

290 In order to test the independence of the calf data, it was necessary to 291 see whether calf sex depended on the sex of the previous calf. The term sex 292 may refer to male or female in single births, and male/male, female/female 293 or male/female in twin births, so calf sex and previous calf sex have five 294 categories. The Kruskal-Wallis test was carried out. Calf sex was used as 295 the grouping variable, whereas the number of births which follow the 296 previous calf sex as the continuous variable. The null hypothesis 297 establishes the same abundance of the five possible births, and the test was 298 run five times, one for each of the categories of the previous calf sex. The 299 hypothesis was not rejected, and the statistics corrected for ties were the 300 same in the five occasions (Kruskal-Wallis test: $\mathrm{df}=4, \mathrm{H}=4.0, \mathrm{p}=0.41$ ).

\section{DISCUSSION}

\section{Introducing the Arguments}

305 High social status facilitates priority of access to resources (mating, food), 306 and diminishes risks by providing a more predictable social environment 307 (Wilson 1975). As a direct consequence of this statement, high ranking 308 individuals should be in better physical condition than low ranking ones 309 (see, e.g., Iwamoto 1988; Soumah and Yokota 1991). In a previous study 310 on the Saharan arrui, I pointed out the lack of a relationship between 311 physical characteristics (body weight and length) and social rank in adult 312 females (Cassinello 1995), an unexpected result, probably due to the 
313 conditions of captivity, where food resources are constant. On the other

314 hand, the phenotypic variables used might not be reliable enough to

315 measure slight differences in the general welfare state of captive animals.

316 Indeed, in this subspecies, high ranking females were primiparous earlier

317 than low ranking ones (Cassinello 1994). This may well indicate a positive

318 relationship between the nutritional state of an individual and the

319 hierarchical position acquired, as nutritional state and age at first birth are

320 usually negatively related (see Sadleir 1969; Bailey 1991). Moreover,

321 behavioural evidence in the study population (stress, feeding preference,

322 etc.; pers. obs.) and available empirical data in other ungulate species

323 (Clutton-Brock et al. 1984; Lott and Galland 1987; Kojola 1989; Orgeur et

324 al. 1990; Alados and Escós 1992) emphasize a positive relationship

325 between social status and maternal investment. Thus, we could expect a

326 differing maternal investment in female arruis of different social status,

327 which may cause biased sex ratios at birth and a sex-biased investment

328 (Trivers and Willard 1973; Clutton-Brock et al. 1981, 1984).

329 Mother's control of postnatal investment is high, for she nearly

330 always determines average suckling duration (pers. obs.; see also Hogg et

331 al. 1992). Only at a very early age, when calves are very weak and

332 probably tire quickly, may they finish a suckling event spontaneously;

333 although, under their mother's encouragement, they keep on suckling

334 afterwards (pers. obs.; see however Birgersson and Ekvall 1994). It is also

335 noticeable that the average suckling rate plays a predominant role in

336 mother's control of the investment as compared with the suckling duration

337 (see Hogg et al. 1992). The average suckling rate decreases with calf's age

338 at a higher rate than average suckling duration, so that the former

339 predominantly accounts for the decrease of maternal investment as in other

340 mammals (White and Luick 1984; Gauthier and Barrette 1985; Robbins et 
341 al. 1987; Stewart 1988; Becker and Ginsberg 1990; Birgersson and Ekvall 342 1994).

343 The average suckling rate is significantly higher during the first 344 month of a calf's life than during the rest of the lactation period, decreasing

345 uniformly from then on; but average suckling duration stops decreasing 346 from the second month on (average=18 seconds). On the other hand, short347 duration suckles are quite common during the first stage of lactation (pers. 348 obs.), which may help to establish and maintain a close mother-calf bond 349 by increasing olfactory, touching, visual and acoustic stimuli (Gubernick 350 1981; Prescott 1981).

352 Differing Behaviour of High Ranking Mothers towards Sons and 353 Daughters

354 In this study high ranking mothers were shown to allocate more of their 355 resources towards male calves, as the average suckling rate was 356 significantly higher in sons than in daughters during their first month of 357 life, when maternal investment reached the highest values of the whole 358 lactation period. The maternal input measure (sensu Evans 1990) used, the 359 average suckling rate, correlated with the inter-birth interval, so that it is a 360 valid measure of maternal investment. This result supports other evidence 361 of biased maternal investment found in the Saharan arrui, where high 362 ranking females were shown to give birth to heavier males than low 363 ranking ones (Cassinello 1994).

364 In relation to the sniffing behaviour, Horejsi (1976, in Hass 1990) 365 suggests that those mothers which frequently sniff their calves are better 366 mothers, confering a higher survival rate on them. Hass (1990), however, 367 states that this sort of behaviour may indicate, at most, a degree of maternal 368 "attentiveness" towards her calves, without necessary indicating the quality 369 of maternal care. A clear distinction between terms like "care" and 
370 "attention", and "maternal investment" must be taken into account, in order

371 to prevent confusing simple maternal caring behaviours, which do not

372 imply reproductive costs, with actual investment. In the Saharan arrui, 373 grooming behaviours are correlated with the average suckling rate, which 374 may imply some relationship between these events and the degree of 375 investment given to the calves.

376 It has also been found that high ranking females spend more time 377 with their sons than with their daughters and are more willing to maintain 378 proximity to them; but it is premature to assume that these behaviours also 379 reflect maternal investment, as there is no evidence about their 380 reproductive costs. The significant bias in favour of sons in high ranking 381 mothers reflects preferential investment, and therefore also indicates the 382 tendency, confirmed above, towards higher investment in male calves.

\section{High and Low Ranking Mothers Differing as a Group}

385 The second issue to be considered here is that high ranking females deliver 386 a greater proportion of male calves than low ranking ones, so that Trivers $387 \&$ Willard's (1973) postulate on polygynous mammals is fulfilled, i.e. the 388 adaptive adjustment of the sex ratio at birth. This has already been shown 389 in other species (e.g. Clutton-Brock et al. 1984; Meikle et al. 1984). On the 390 other hand, the lack of any relationship between calf sex and the following 391 inter-birth interval means that the cost of raising either sexes does not vary 392 significantly under captive conditions (cf. e.g. Gomendio 1990).

393 The results obtained also show a clear distinction between high and 394 low ranking mothers when allocating the resources to their calves. While 395 high ranking mothers are more discriminating as a function of calf sex (see 396 above), low ranking ones are not, as they equally invest in sons and 397 daughters. Interestingly, no particularly high aggression level on low 398 ranking mothers has been seen in the study population (Cassinello 1994), 
399 even when splitting the analysis by calf sex (Cassinello, unpublished data),

400 so that Gomendio's (1990) arguments on rhesus macaques cannot be 401 applied here, as the differences on the level of maternal investment in 402 mothers of differing social status in the Saharan arrui depend on the 403 energetic demands of rapidly growing sons, and not on the level of 404 aggression suffered by the mothers (see Clutton-Brock et al. 1984; 405 Gomendio 1990).

406

407 Conclusion

408 Following Byers and Moodie (1990), the degree of sexual dimorphism 409 (1.96) and mother-calf average body weight ratio (0.160) of the Saharan 410 arrui would include this subspecies in the group of polygynous ungulates 411 which show biased maternal investment according to Trivers and Willard's 412 (1973) hypothesis. Indeed, the statiscally significant difference between the 413 two groups differentiated by Byers and Moodie (1990) is retained after 414 adding the arrui data (Mann-Whitney test: $\mathrm{N}=12, \mathrm{U}=4, \mathrm{U}^{\prime}=32, \mathrm{p}=0.02$ ).

415 Finally, the investment allocated to sons of high ranking mothers is 416 not particularly greater than that of low ranking ones (see Fig. 3). This 417 raises the question of a hypothetical difference in the "quality" of 418 investment by high and low ranking females. I have no data either to refute 419 or confirm this possibility, so that the question remains open; but, whatever 420 the answer may be, my statement of sex-biased investment in high ranking 421 females would still be valid.

\section{ACKNOWLEDGEMENTS}

424 I am indebted to Fritz Trillmich for valuable comments and critiques which 425 have substantially improved an earlier version of the manuscript. I also 426 wish to thank Montserrat Gomendio and two anonymous referees for their 427 useful comments, as well as the staff of the EEZA for their continuous care 
428 and proper management of the captive animals. During data collection, the 429 author was holding a predoctoral grant awarded by the Spanish Education 430 and Science Ministry.

433 Alados CL, Escós JM (1992) The determinants of social status and the effect of female rank on reproductive success in Dama and Cuvier's gazelles. Ethol Ecol Evol 4: 151-164

Alados CL, Escós J, Vericad JR (1988) Captive populations of northwest African Antilopinae and Caprinae at the Estación Experimental de Zonas Áridas. In Dixon A, Jones D (eds) Conservation and biology of desert antelopes. Christopher Helm Ltd., Kent, pp. 199-211.

440 Alados CL, Vericad JR (1993) Aoudad. Ammotragus lervia from WesternSahara. International Studbook. Boletín del Instituto de Estudios

443 Altmann J (1974) Observational study of behaviour: sampling methods. Behaviour 49: 227-267

445 Bailey JA (1991) Reproductive success in female mountain goats. Can J 446 Zool 69: 2956-2961

447 Ballou J (1983) Calculating inbreeding coefficients from pedigrees. In Schonewald-Cox CM, Chambers SM, MacBryde B, Thomas L (eds) Genetics and Conservation: A Reference for Managing Wild Animal

452 Becker CD, Ginsberg JA (1990) Mother-infant behaviour of wild Grevy's zebra: adaptations for survival in semi-desert East Africa. Anim Behav 40: 1111-1118 
455 Berman CM (1988) Maternal condition and offspring sex ratio in a group 456 of free-ranging rhesus monkeys: an eleven-year study. Am Nat 131: $457 \quad 307-328$

458 Birgersson B, Ekvall K (1994) Suckling time and fawn growth in fallow 459 deer (Dama dama). J Zool 232: 641-650

460 Bulger J, Hamilton WJ III (1987) Rank and density correlates of inclusive 461 fitness measures in a natural chacma baboon (Papio ursinus) troop. Int 463 Byers JA, Moodie JD (1990) Sex-specific maternal investment in 464 pronghorn, and the question of a limit on differential provisioning in 465 ungulates. Behav Ecol Sociobiol 26: 157-164

466 Cassinello J (1994) Exito Reproductivo, Inversión Parental y Conflicto 467 Materno-Filiar en Ammotragus lervia Pallas, 1777. PhD Thesis. 468 University of Granada. 165 pp

469 Cassinello J (1995) Factors modifying female social ranks in Ammotragus. Appl Anim Behav Sci 45: 175-180

471 Cassinello J, Alados CL (1996) Reproductive success in captive Ammotragus lervia (Bovidae, Artiodactyla). Study of its components and effects of hierarchy and inbreeding. J Zool 239: 000-000

474 Clutton-Brock TH (1991) The evolution of parental care. Princeton 475 University Press. Princeton, New Jersey. 352 pp

476 Clutton-Brock TH, Albon SD (1982) Parental investment in male and 477 female offspring in mammals. In King's College Sociobiology Group: RW Wrangham, DI Rubenstein, RIM Dunbar, BCR Bertram and TH 481 Clutton-Brock TH, Albon SD, Guinness FE (1981) Parental investment in 482 male and female offspring in polygynous mammals. Nature 289: 487489 
484 Clutton-Brock TH, Albon SD, Guinness FE (1984) Maternal dominance, 485 breeding success and birth sex ratios in red deer. Nature 308: 358-360 486 Clutton-Brock TH, Albon SD, Guinness FE (1986) Great expectations: 487 dominance, breeding success and offspring sex ratios in red deer. $488 \quad$ Anim Behav 34: 460-471

489 Deutsh JC, Lee PC (1991) Dominance and feeding competition in captive $490 \quad$ rhesus monkeys. Int J Primatol 12: 615-628

491 Evans RM (1990) The relationship between parental input and investment. 492 Anim Behav 39: 797-813

493 Gauthier D, Barrette C (1985) Suckling and weaning in captive white494 tailed and fallow deer. Behaviour 94: 128-149

495 Gomendio M (1990) The influence of maternal rank and infant sex on 496 maternal investment trends in rhesus macaques: birth sex ratios, inter497 birth intervals and suckling patterns. Behav Ecol Sociobiol 27: 365498 375

499 Gomendio M, Clutton-Brock TH, Albon SD, Guinness FE, Simpson MJ 500 (1990) Mammalian sex ratios and variation in costs of rearing sons and daughters. Nature 343: 261-263

502 Gray GG (1985) Status and distribution of Ammotragus lervia: a world503 wide review. In Hoefs M (ed) Wild sheep. Distribution, abundance,

507 Gubernick DJ (1981) Parental and infant attachment in mammals. In 508 Gubernick DJ, Klopfer PH (eds) Parental care in mammals. Plenum, $509 \quad$ New York, pp 243-289

510 Haas G (1959) Untersuchungen über angeborene Verhaltensweisen bei 511 Mähnenspringern (Ammotragus lervia Pallas). Z Tierpsychol 16: 218242 
513 Habibi K (1987) Behaviour of aoudad (Ammotragus lervia) during the rut-

514 ting season. Mammalia 51: 497-513

515 Hass CC (1990) Alternative maternal-care patterns in two herds of bighorn 516 sheep. J Mammal 71: 24-35

517 Hinde RA, Atkinson S (1970) Assessing the roles of social partners in 518 maintaining mutual proximity, as exemplified by mother-infant rela519 tions in rhesus monkeys. Anim Behav 18: 169-176

520 Hogg JT, Hass CC, Jenni DA (1992) Sex-biased maternal expenditure in 521 Rocky Mountain bighorn sheep. Behav Ecol Sociobiol 31: 243-251

522 Iwamoto $\mathrm{T}$ (1988) Food and energetics of provisioned wild Japanese macaques (Macaca fuscata). In Fa JE, Southwick CH (eds) Ecology and behaviour of food-enhanced primate groups. Monogr. Primatol. Vol. 11, New York, Liss, pp 79-94

Johnson RL, Malik I, Berman CM (1991) Ageand dominance-related variation in feeding time among free-ranging female rhesus monkeys. Int J Primatol 12: 337-356

531 Lamprecht J (1986) Structure and causation of the dominance hierarchy in 532 a flock of bar-headed geese (Anser indicus). Behaviour 96: 28-48.

533 Lickliter R (1984) Mother-infant spatial relationships in domestic goats. 534 Appl Anim Behav Sci 13: 93-100

535 Lott DF, Galland JC (1987) Body mass as a factor influencing dominance 536 status in American bison cows. J Mammal 68: 683-685

537 Martin P, Bateson P (1986) Measuring behaviour. An introductory guide. 538 Cambridge Univ. Press, Cambridge. 200 pp

539 Meikle DB, Tilford BL, Vessey SH (1984) Dominance rank, secondary sex 540 ratio, and reproduction of offspring in polygynous primates. Am Nat 124: $173-188$ 
542 Orgeur P, Mimouni P, Signoret JP (1990) The influence of rearing 543 conditions on the social relationships of young male goats (Capra hircus). Appl Anim Behav Sci 27: 105-113

545 Prescott J (1981) Suckling behaviour of llama (Lama glama glama) and

546 Chapman's zebra (Equus burchelli antiquorum) in captivity. Appl $547 \quad$ Anim Ethol 7: 293-299

548 Ralls K, Lundrigan B, Kranz K (1987) Mother-young relationships in 549 captive ungulates: spatial and temporal patterns. Zoo Biol 6: 11-20

550 Reiter J, Stinson NL, Le Boeuf BJ (1978) Northern elephant seal 551 development: the transition from weaning to nutritional development. $552 \quad$ Behav Ecol Sociobiol 3: 337-367

553 Robbins CT, Oftedal OT, O'Rourke KI (1987) Lactation, early nutrition, 554 and handrearing of wild ungulates, with special reference to deer. In 555 Wemmer CM (ed) Biology and management of the Cervidae.

557 Sadleir RMFS (1969) The ecology of reproduction in wild and domestic 558

562 Soumah AG, Yokota N (1991) Female rank and feeding strategies in a 563 564

565 Stewart KJ (1988) Suckling and lactational anoestrus in wild gorillas 566 (Gorilla gorilla). J Reprod Fertil 83: 627-634

567 Trivers RL (1972) Parental investment and sexual selection. In Campbell B 568 (ed) Sexual selection and the descent of man, 1871-1971. Aldine, $569 \quad$ Chicago, pp 136-179 
570 Trivers RL, Willard DE (1973) Natural selection of parental ability to vary

571 the sex ratio. Science 179: $90-92$

572 White RG, Luick JR (1984) Plasticity and constraints in the lactational

573 strategy of reindeer and caribou. Symp zool Soc Lond 51: 215-232

574 Wierenga HK (1990) Social dominance in dairy cattle and the influence of 575 housing and management. Appl Anim Behav Sci 27: 201-229

576 Wilson EO (1975) Sociobiology. The new synthesis. The Belknap Press of

$577 \quad$ Harvard University Press, Cambridge, Massachusetts. 697 pp

578 Wright $S$ (1922) Coefficients of inbreeding and relationship. Am Nat 56: $579 \quad 330-338$

580 Zar JH (1984) Biostatistical analysis. Second edition, Prentice-Hall, Inc., $581 \quad$ Englewood Cliffs, New Jersey. 718 pp 


\section{FIGURE LEGENDS}

Fig. 1. Relationship between the average suckling rate during the whole lactation period and the interval of time to the next birth.

Fig. 2. Monthly suckling behaviour: duration (a) and suckling rate (b).

Fig. 3. Suckling rate (mean $+\mathrm{SE}$ ) of one month-old calves, for two maternal rank groups and according to calf sex.

Fig. 4. Weekly values of Hinde's proximity index (mean + SE).

Fig. 5. Relationship between monthly Hinde's proximity index during calves' first month, and maternal rank. The continuous regression line corresponds to male calves and the discontinuous one to female calves.

Fig. 6. Proportion of time (mean $+\mathrm{SE})$ per sample spent by mothers and calves at different distances (in body-lengths) during calves' first month of life, and for two maternal rank groups.

Fig. 7. Proportion of time (mean $+\mathrm{SE})$ per sample spent by mothers and calves at 0-1 body-lengths during calves' first month, according to calf sex and for two maternal rank groups.

Fig. 8. The percentage of male calves produced by individual females as a function of the average maternal rank.

Fig. 9. The number of male calves produced by individual females as a function of the average maternal rank.

Fig. 10. The number of female calves produced by individual females as a function of the average maternal rank. 


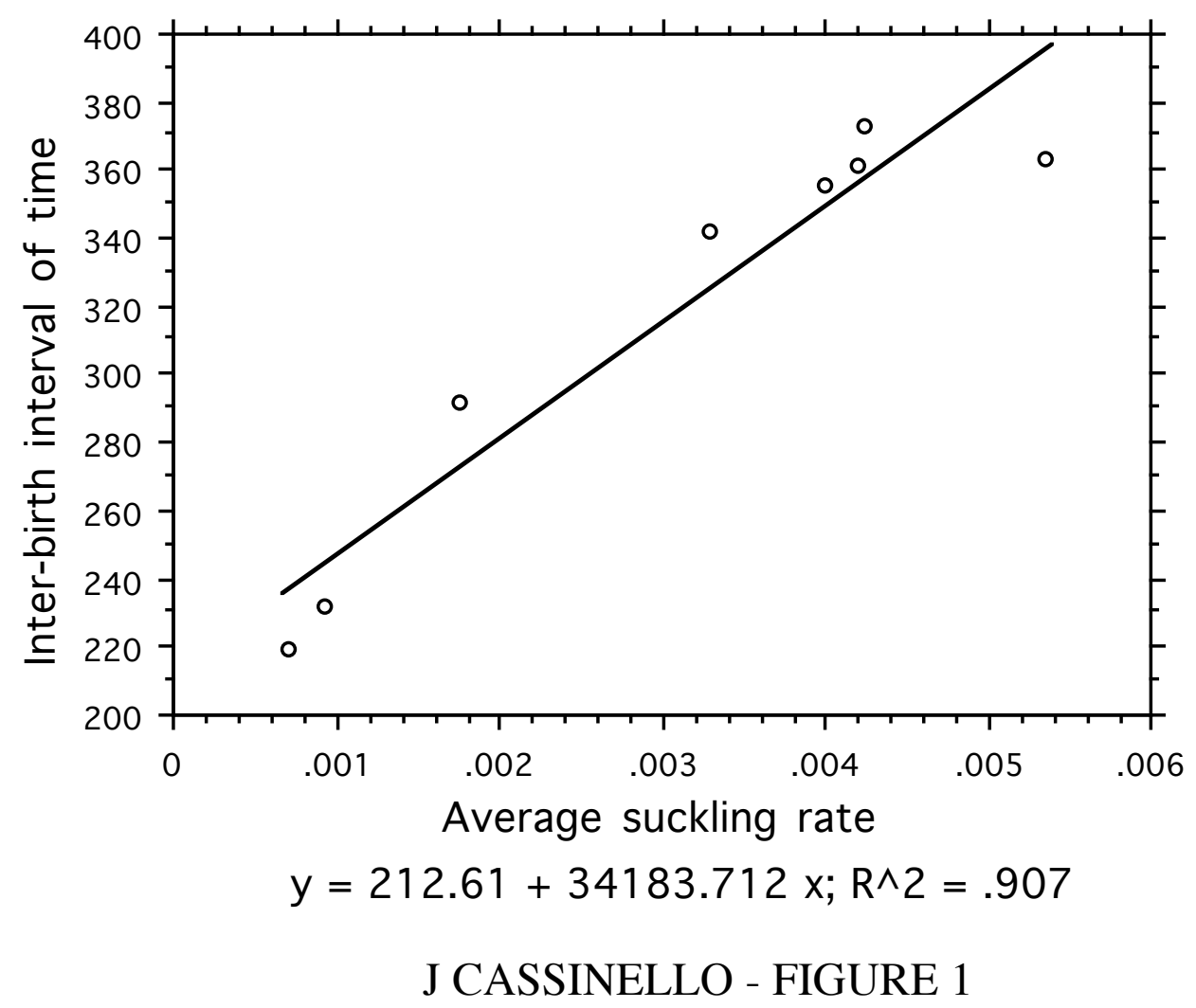



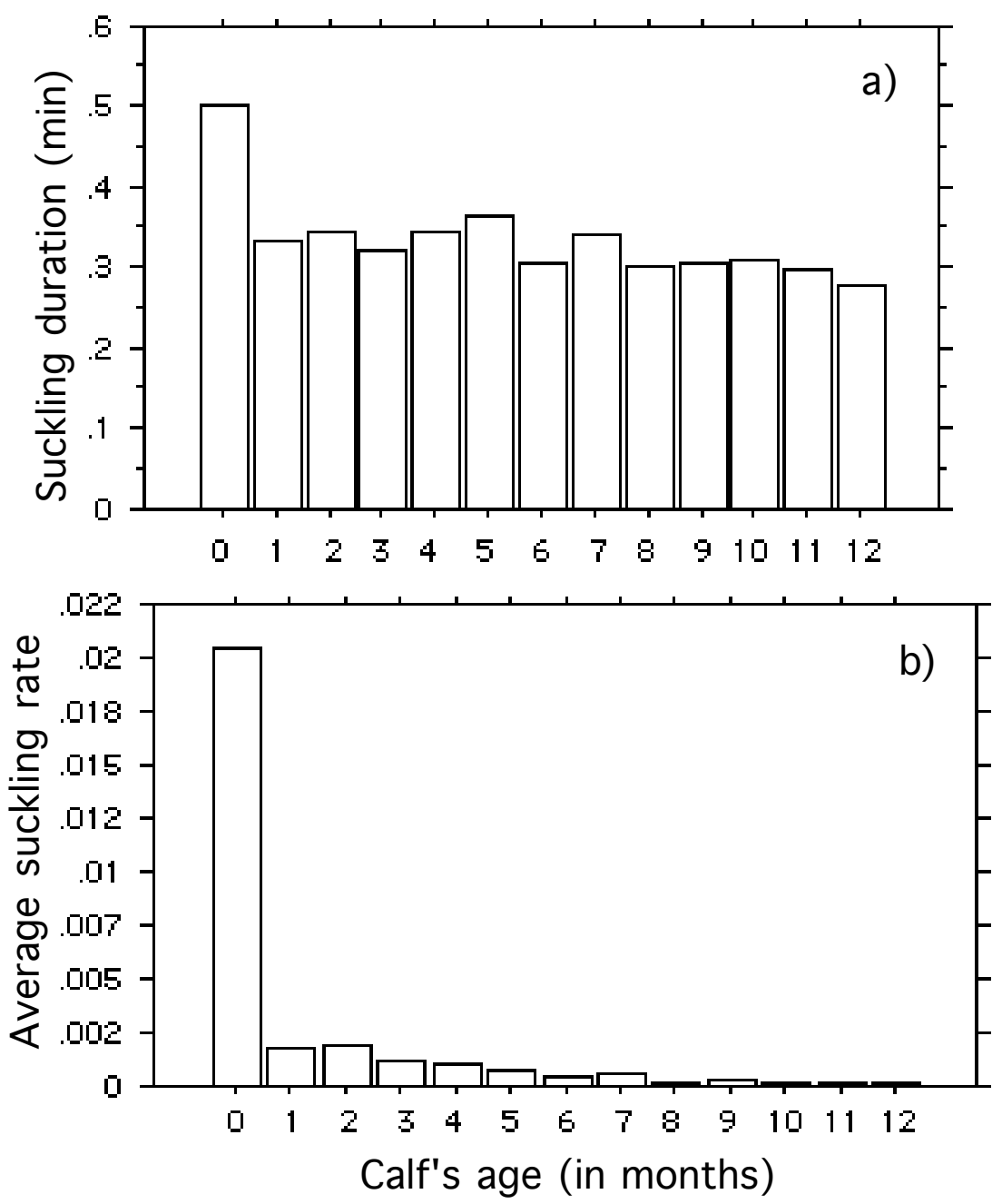

J CASSINELLO - FIGURE 2 


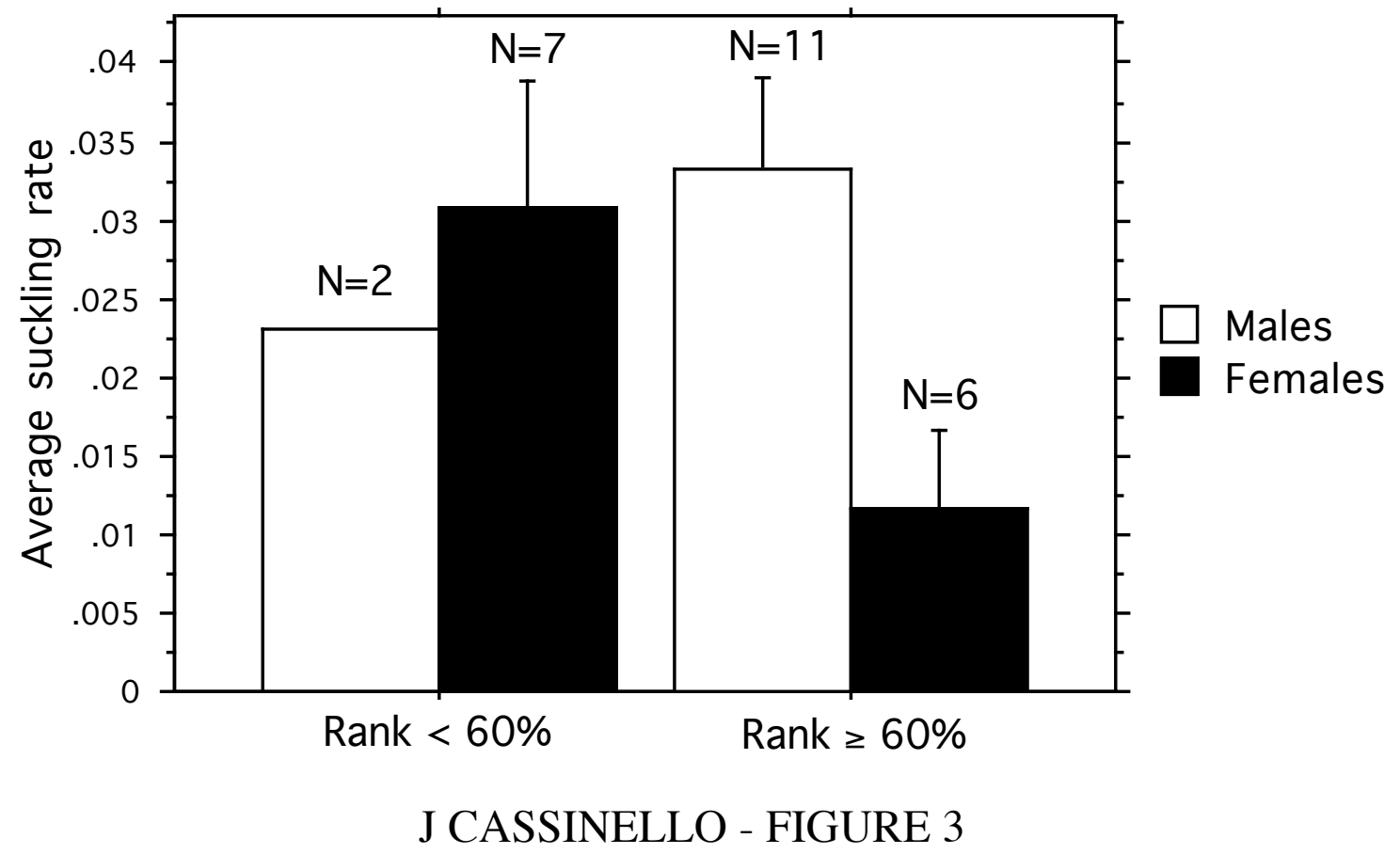




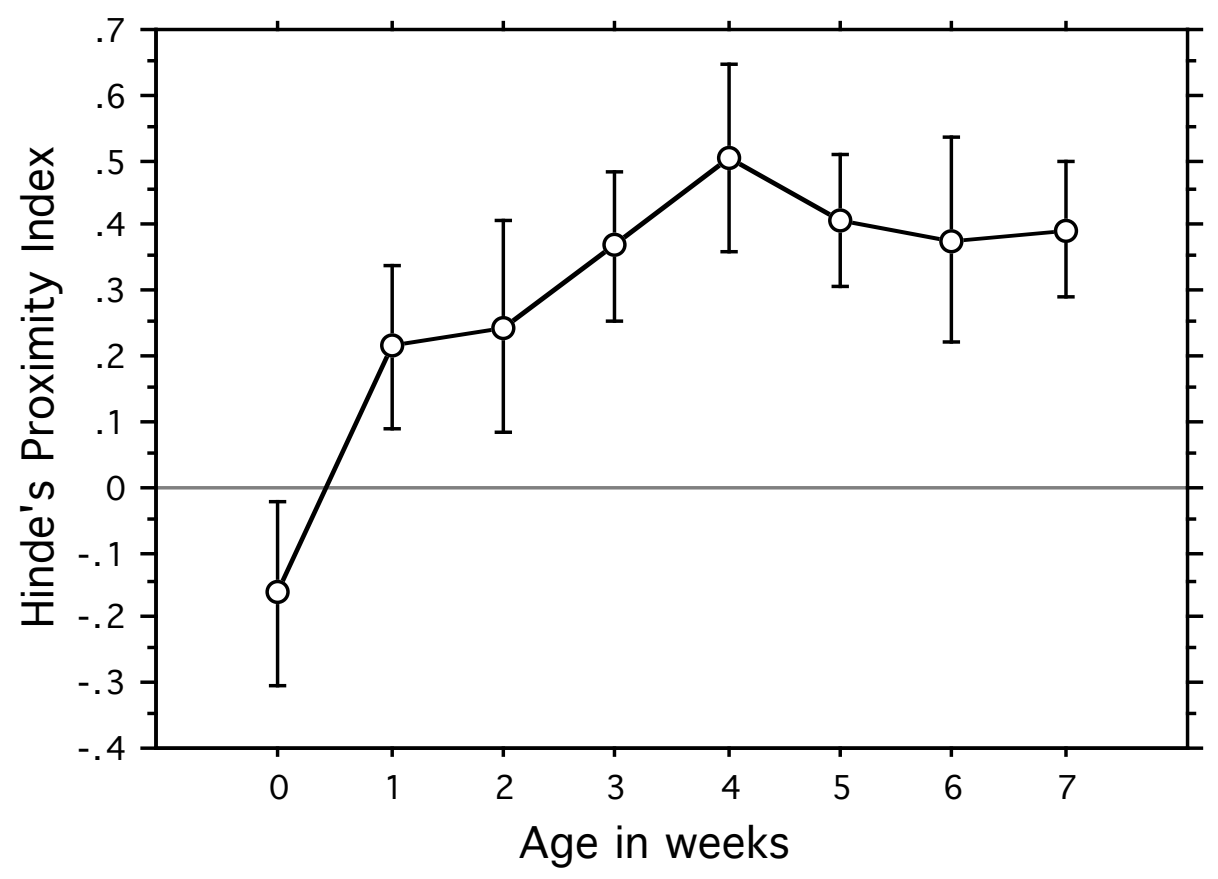

J CASSINELLO - FIGURE 4 


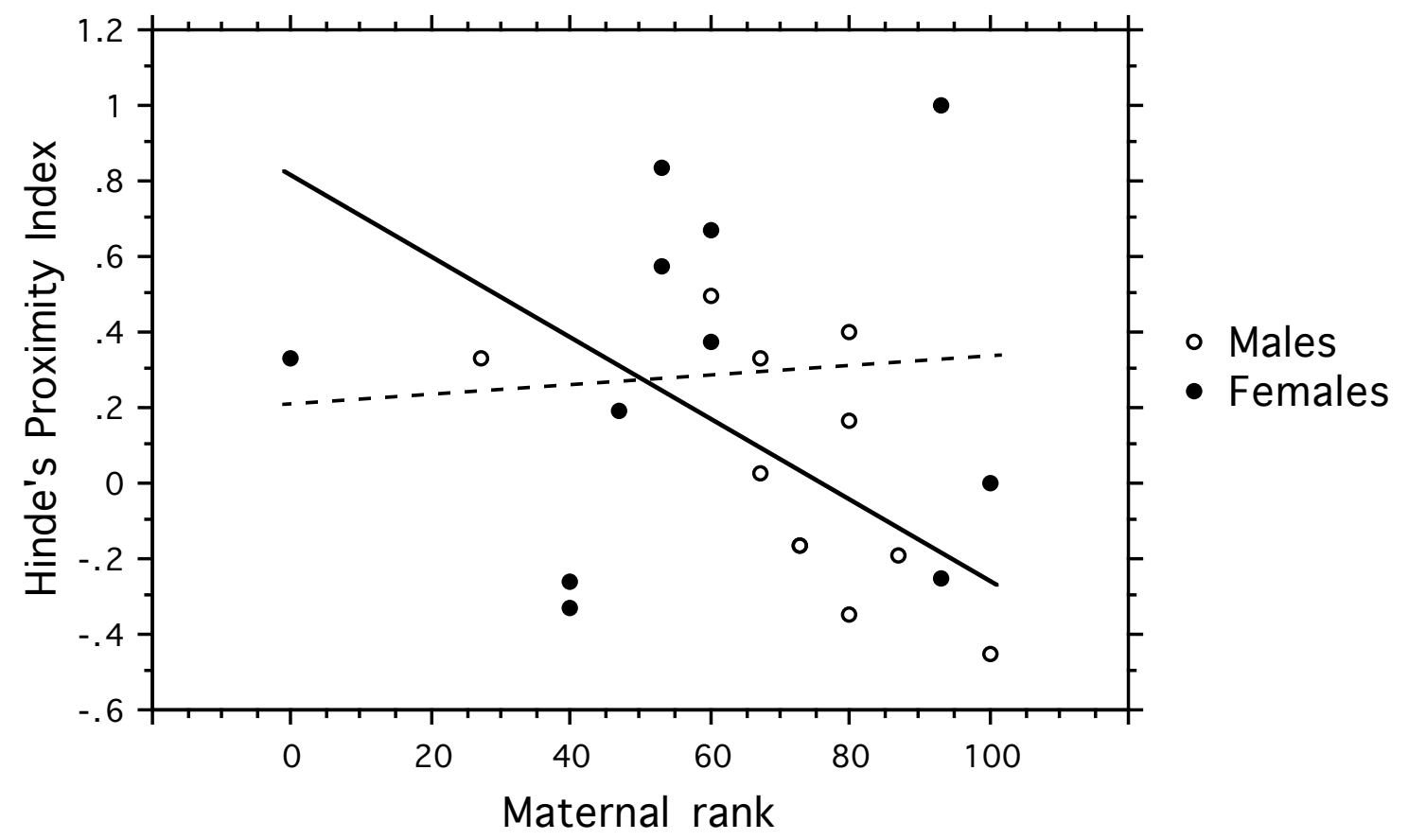

J CASSINELLO - FIGURE 5 


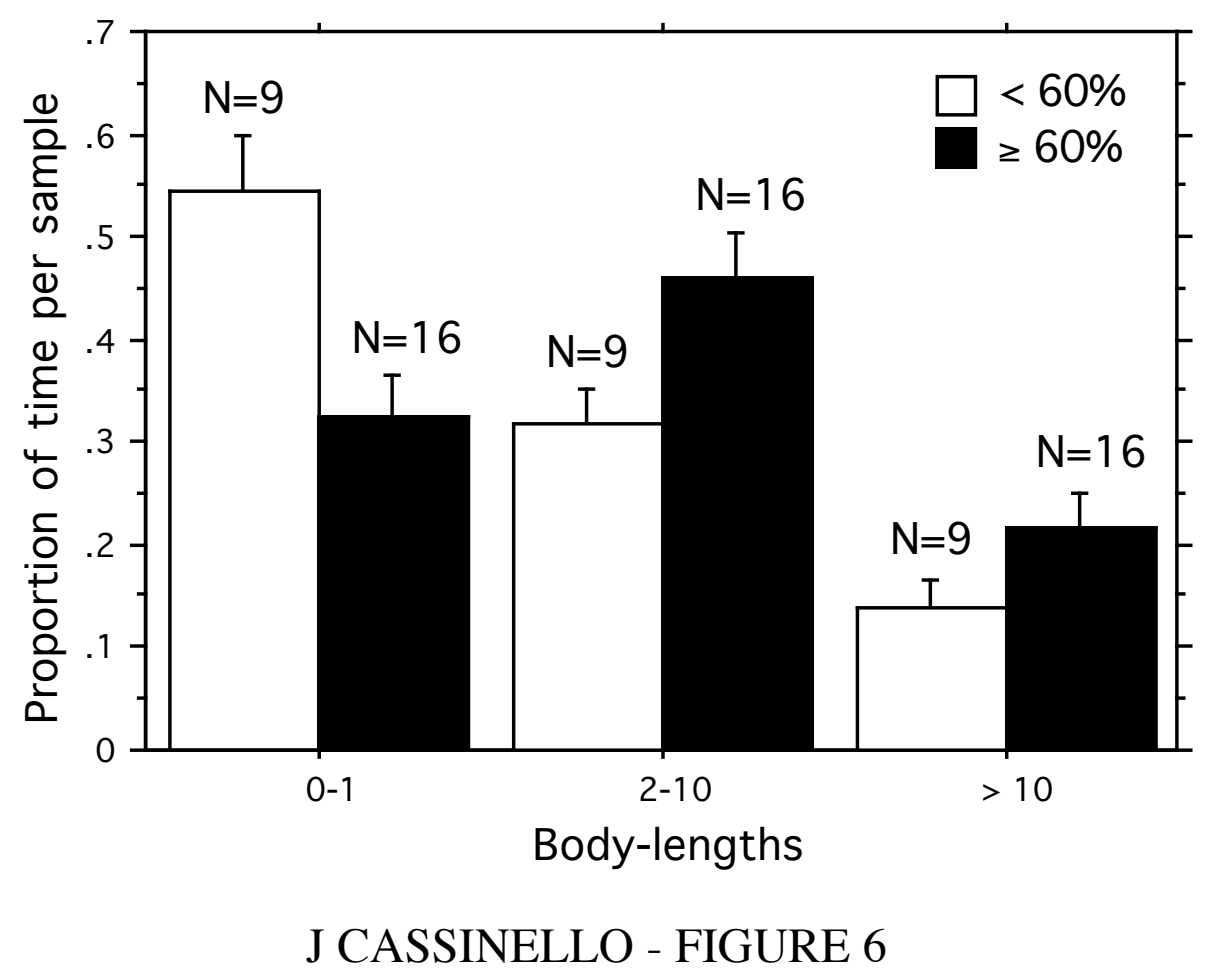




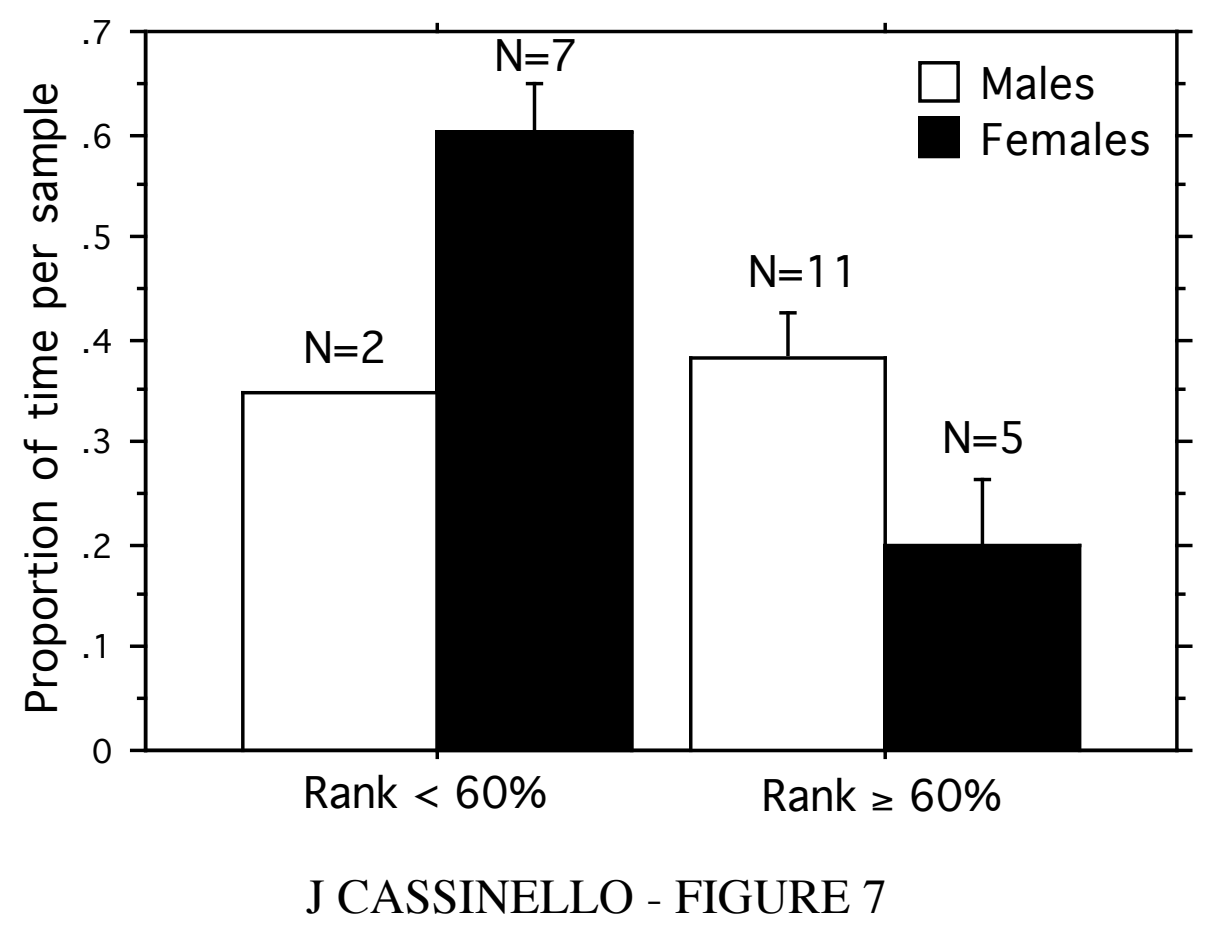




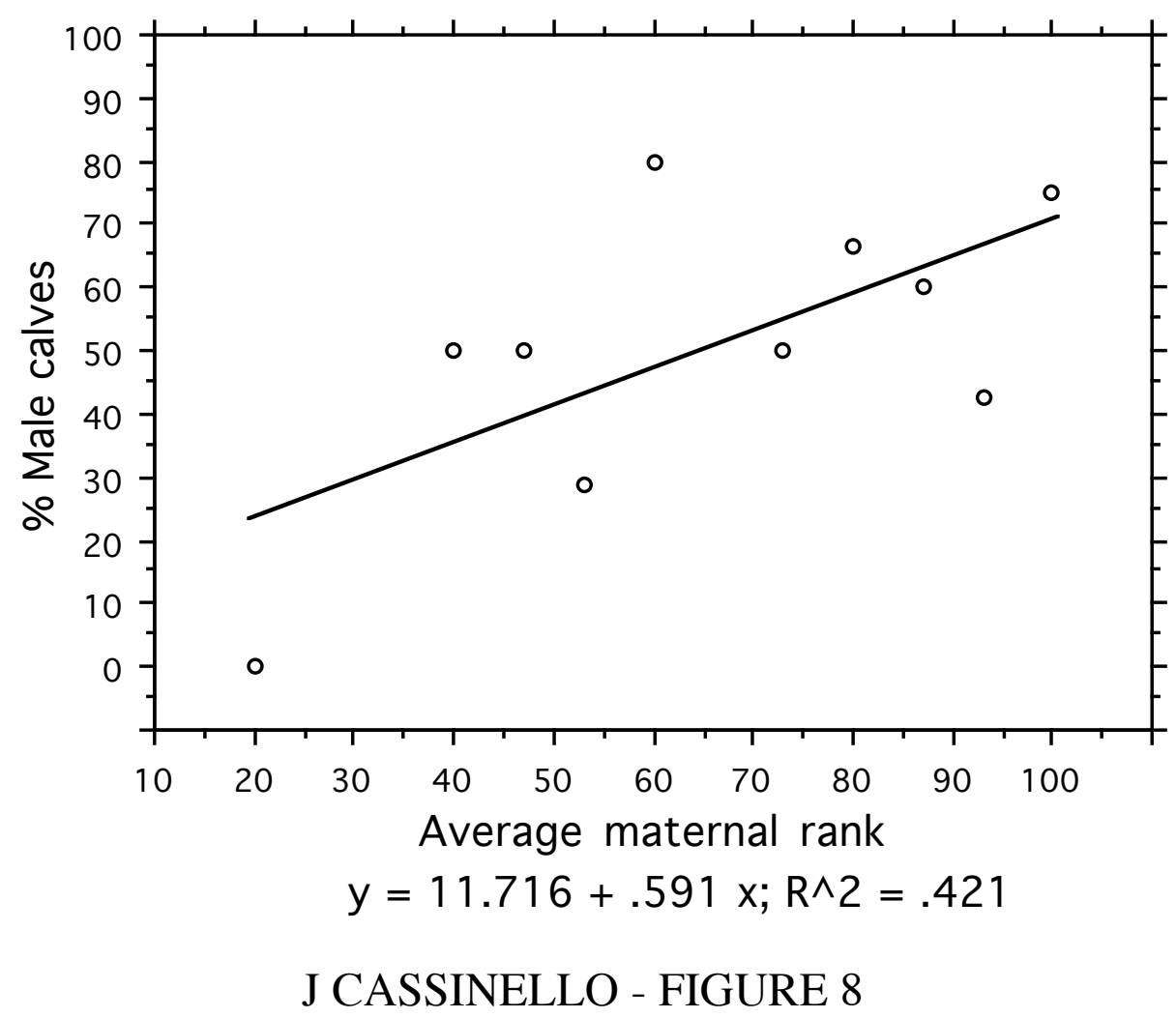




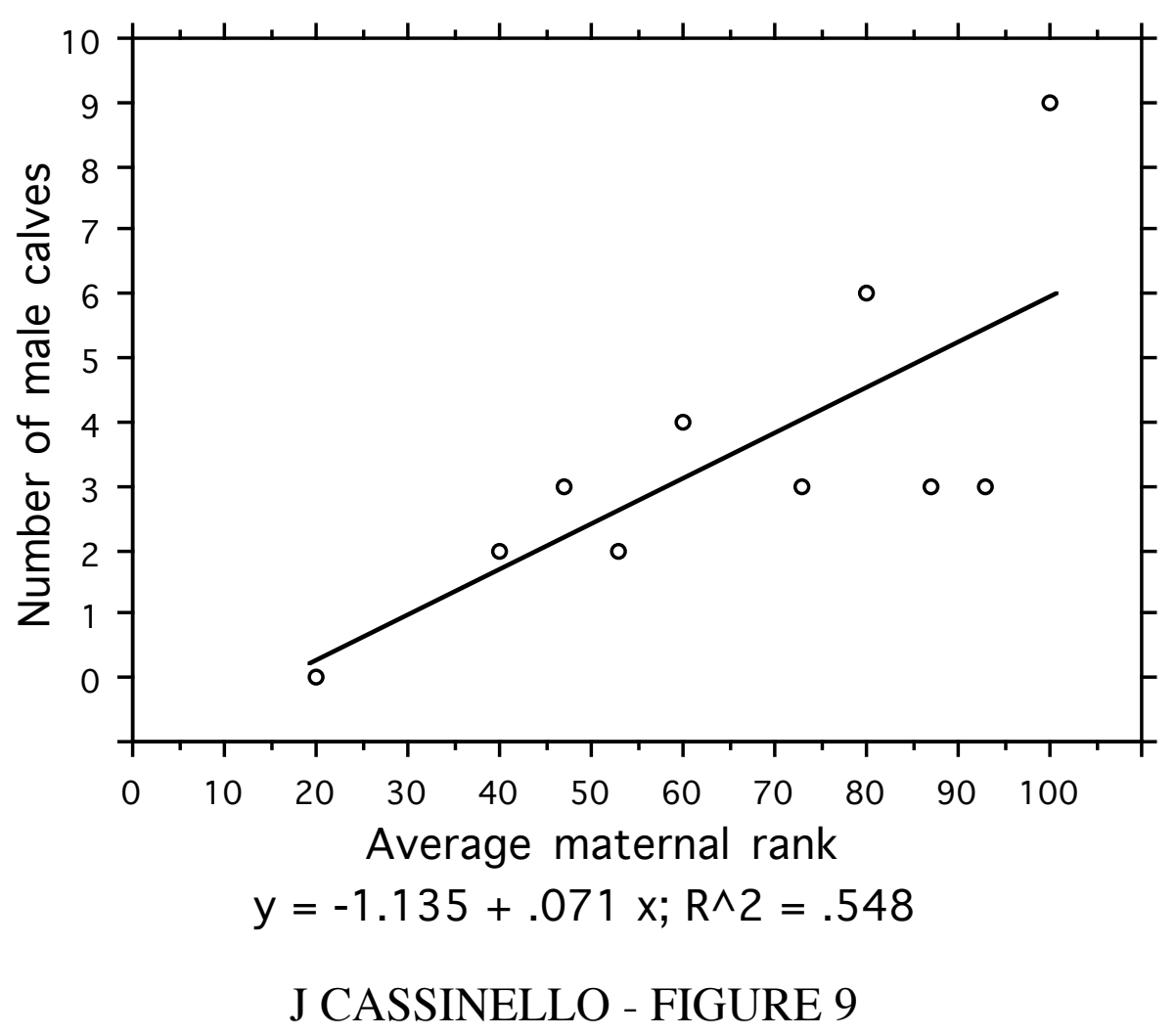




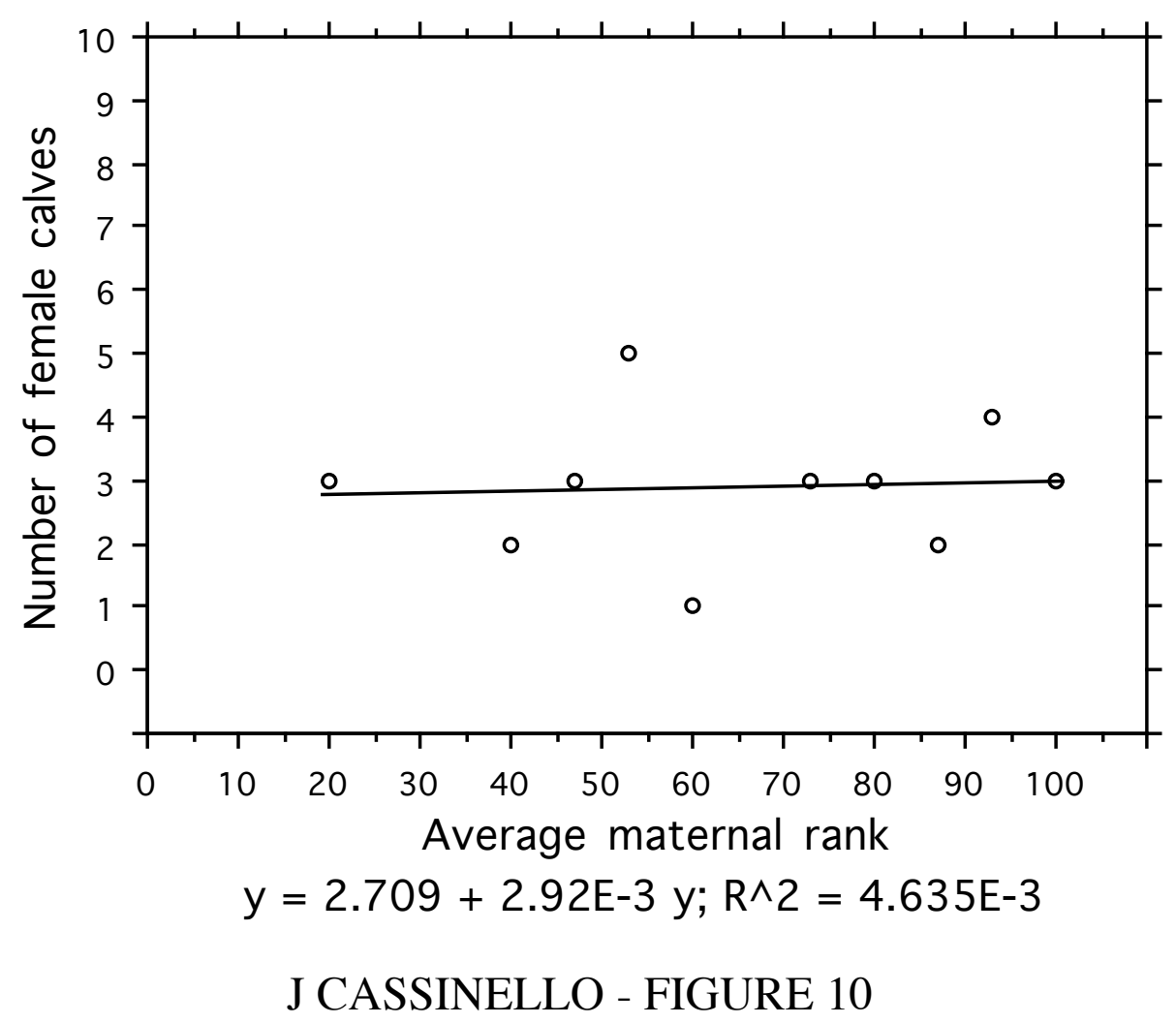

